\begin{tabular}{|c|c|}
\hline Title & Effects of calcium leaching on diffusion properties of hardened and altered cement pastes \\
\hline Author(s) & Kurumisawa, Kiyofumi; Haga, Kazuko; Hay ashi, Daisuke; Owada, Hitoshi \\
\hline Citation & $\begin{array}{l}\text { Physics and Chemistry of the Earth, Parts A B C, 99, 175-183 } \\
\text { https://doi.org/10.1016/.pce.2017.03.007 }\end{array}$ \\
\hline Issue Date & $2017-06$ \\
\hline Doc URL & http:/hdl.handle.net/2115/74510 \\
\hline Rights & 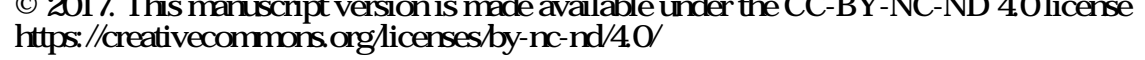 \\
\hline Rights(URL) & https://reativecommons.org/icenses/by-nc-nd/4.0/ \\
\hline Type & article (author version) \\
\hline File Information & paper0216.pdf \\
\hline
\end{tabular}

Instructions for use 


\title{
EFFECTS OF CALCIUM LEACHING ON DIFFUSION PROPERTIES OF HARDENED AND ALTERED CEMENT PASTES
}

Kurumisawa, K. ${ }^{1)}$, Haga, K. ${ }^{2)}$, Hayashi, D. ${ }^{3)}$, Owada, H. ${ }^{3)}$

1) Hokkaido University, Faculty of engineering, Kita 13, Nishi 8, Kita-ku, Sapporo 060-8628, Japan

2) Taiheiyo Consultant Co., 2-27-8, Higashinihonbashi, Chuo-ku, Tokyo 103-0004, Japan

3) Radioactive Waste Management Funding and Research Center, 1-15-7, Tukishima, Chuo-ku, Tokyo 104-0052, Japan

Corresponding author: Kurumisawa, K., email: kurumi@eng.hokudai.ac.jp

\begin{abstract}
It is very important to predict alterations in the concrete used for fabricating disposal containers for radioactive waste. Therefore, it is necessary to understand the alteration of cementitious materials caused by calcium leaching when they are in contact with ground water in the long term. To evaluate the long-term transport characteristics of cementitious materials, the microstructural behavior of these materials should be considered. However, many predictive models of transport characteristics focus on the pore structure, while only few such models consider both, the spatial distribution of calcium silicate hydrate (C-S-H), portlandite, and the pore spaces. This study focused on the spatial distribution of these cement phases. The auto-correlation function of each phase of cementitious materials was calculated from two-dimensional backscattered electron imaging, and the three-dimensional spatial image of the cementitious material was produced using these auto-correlation functions. An attempt was made to estimate the diffusion coefficient of chloride from the three-dimensional spatial image. The estimated diffusion coefficient of the altered sample from the three-dimensional spatial image was found to be comparable to the measured value. This demonstrated that it is
\end{abstract}


possible to predict the diffusion coefficient of the altered cement paste by using the proposed model.

\section{Introduction}

In order to provide safe, environmentally sound solutions to managing radioactive waste, it is very important to predict alterations in cementitious materials, such as concrete used for fabricating disposal containers for radioactive waste. Therefore, it is necessary to understand the alteration of cementitious materials caused by calcium leaching when they are in contact with ground water in the long term, e.g., ten thousand years. Calcium leaching in this period leads to a change of macro properties and microstructure in cementitious materials. To evaluate the long-term transport properties of cementitious materials, the microstructural behavior of these materials, such as alteration by calcium leaching, should be considered. However, many predictive models of transport characteristics focus only on the pore structure (Iqbal and Ishida, 2009; Bejaoui and Bary, 2007; Yokozeki et al., 2004), while only few such models consider the spatial distribution of calcium silicate hydrate (C-S-H), portlandite, and the pore spaces. Although X-ray CT has been proposed for measuring the spatial distribution of the phases, its resolution is insufficient for measuring the extent of calcium leaching (Burlion et al., 2006; Wan et al., 2012; Wan et al., 2013). Laser scanning confocal microscopy (LSCM) has been proposed to produce three-dimensional images of cementitious material; thus, this method would make it possible to detect particles in the sub-micron range (Yio et al., 2015). However, it is difficult to distinguish between hydrate products such as C-S-H and portlandite by LSCM (Head and Buenfeld, 2006). As previously mentioned, it is difficult to get real three-dimensional images of cementitious materials at the micro level; to overcome this difficulty, a statistical method was applied to reconstruct a three-dimensional image of cementitious materials from a previous study (Kurumisawa et al., 2012). The authors of a previous study investigated the diffusivity of a non-altered hardened cement paste using a three-dimensional spatial image model. This model was reconstructed with the auto-correlation function calculated based on a backscattered electron image of hardened cement paste, thus clarifying the effect of diffusivity of $\mathrm{C}-\mathrm{S}-\mathrm{H}$ on 
diffusivity of hardened cement paste. However, this method has not been applied to an altered hardened cement paste such as calcium leaching; the effect of calcium leaching on diffusivity of hardened cement paste is not clarified. This study focused on the spatial distribution of the cement phases in an altered cement paste with calcium leaching. The three-dimensional spatial image of these materials was produced by using these auto-correlation functions. Finally, we attempted to estimate the diffusivity of the altered cement paste by using a finite difference method in conjunction with the three-dimensional spatial image.

\section{Experimental}

\subsection{Sample preparation}

Ordinary Portland cement (OPC) produced in Japan was used in this study. The density of OPC is $3170 \mathrm{~kg} / \mathrm{m}^{3}$ and the Blaine surface area is $3340 \mathrm{~cm}^{2} / \mathrm{g}$. The chemical composition of OPC is listed in Table 1 . The water-to-cement ratio for the hardened cement pastes (HCP) was maintained at 0.6 (RWMC., 2013) to prevent the effect of unhydrated cement on the experimental results and to produce a lower $\mathrm{CaO} / \mathrm{SiO}_{2}$ ratio specimen by leaching. After mixing, the specimens were poured into a mold where they cured for $24 \mathrm{~h}$. After $24 \mathrm{~h}$, the specimens were demolded and cured at $50{ }^{\circ} \mathrm{C}$ in a saturated calcium hydroxide solution for 91 days to accelerate the hydration of the cement. An ammonium nitrate solution was used to accelerate the alternation of the hardened cement paste, and the degree of alternation of the paste was simulated by changing the concentration of the ammonium nitrate solution (Carde and François, 1997; Moranville et al., 2004). As a result, this produced hardened cement pastes having different $\mathrm{CaO} / \mathrm{SiO}_{2}$ ratios. In this study, the concentrations of the ammonium nitrate solution (specimen weight: $\mathrm{NH}_{4} \mathrm{NO}_{3}$ solution weight $=1: 30$ ) used were $0.25,0.4$, and $0.6 \mathrm{M}$, respectively, as listed in Table 2, and the immersion time was 7 days without renewal of the solution. The specimens were cut from the center of bulk samples $(30 \mathrm{~mm}$ in diameter and 100 $\mathrm{mm}$ in height) and the specimens used for immersion were $3 \mathrm{~mm}$ thick and $30 \mathrm{~mm}$ in diameter to produce a homogeneous alternation of the specimens. After immersion, we measured the $\mathrm{CaO} / \mathrm{SiO}_{2}$ ratios (non-altered, 0.25, 0.4, and $0.6 \mathrm{M}$ were $3.2,1.8,1.3$, and 1.0 , respectively) at the cross-sections of the specimens by 
using an electron probe micro analyzer (EPMA), as shown in Figure 1, and confirmed that the samples were homogeneous. The concentration of elements in specimens was determined by standard material (Wollastonite) and the degree of $\mathrm{CaO}$ leaching was calculated from the $\mathrm{CaO}$ concentration as measured by the EPMA.

\subsection{Measurement of backscattered electron image (BEI)}

After the $\mathrm{NH}_{4} \mathrm{NO}_{3}$ immersion, specimens were immersed in deionized water to remove the $\mathrm{NH}_{4} \mathrm{NO}_{3}$ solution for 1 day, and we immediately applied the freeze-dry method (liquid nitrogen for freezing and vacuumed in less than $10 \mathrm{~Pa}$ ). A 3-mm cube was cut from freeze-dried samples of the hardened cement pastes and was used for BEI observations. The freeze-dried specimens were immersed in epoxy resin in a vacuum to maintain the microstructure of the specimen; once the resin hardened, the specimen surface was polished using SiC paper (grid sizes 800, 1000, 1500, 2000, 3000 , and 5000). Finally, the surfaces of the specimens were smoothed by a $0.25-\mu \mathrm{m}$ diamond paste (Scrivener et al., 2015), and a carbon coat was applied to provide electric conductivity to the specimen surfaces. Electron microscopy imaging was conducted under the following conditions: an acceleration voltage of $15 \mathrm{keV}$, a working distance of $17 \mathrm{~mm}$, an area of $200 \times 150 \mu \mathrm{m}$, and a pixel size of $0.32 \mu \mathrm{m}$. The resolution obtained in this study was $0.32 \mu \mathrm{m}$; it was not possible to distinguish between pores narrower than $0.32 \mu \mathrm{m}$ in diameter. We adjusted the brightness of the image based on the brightness of the epoxy resin and unhydrated cement. Observations were carried out on 16 points on each specimen. Unhydrated cement (UH), unhydrated calcium hydroxide $(\mathrm{CH}), \mathrm{C}-\mathrm{S}-\mathrm{H}$ (including fine pores and other hydrates), and pores larger than $0.32 \mu \mathrm{m}$ were distinguished using image analysis software and by setting brightness thresholds. Each phase was separated by the threshold, which is the minimum value of brightness between the peaks of two phases. The average area fraction of each phase was considered the volume fraction (Igarashi et al., 2004), and the standard deviation of each phase in every sample was less than 0.06 .

\subsection{Measurement of the micro elastic modulus using a micro-indentation method}

The specimens for indentation analysis were the same specimens as those used for the BEI. A Fischers scope (HC-100) was used for measuring the micro elastic modulus of the hydration products in the hardened cement paste. One hundred 
indents in a $10 \times 10^{-\mu m}$ grid were sampled in each specimen, consistent with the previous report (Kurumisawa et al., 2013a). The maximum load and rate of loading were observed to be $20 \mathrm{mN}$ and $1 \mathrm{mN} / \mathrm{s}$, respectively. The micro elastic modulus can be calculated based on the inclination measured upon removing the load, in accordance with Oliver (Oliver and Pharr, 1992; Zhu and Bartos, 2000). After the measurements, the indents were observed using microscopy to distinguish among the different phases (UH, CH, C-S-H, and others).

\subsection{Diffusion coefficient measurements}

The diffusion cell method was used to measure the diffusion coefficients of $30-\mathrm{mm}$ diameter, $5-\mathrm{mm}$ thick specimens. One side of the cell was filled with $0.5 \mathrm{~mol} / \mathrm{L} \mathrm{NaCl}$ solution and the other side was filled with saturated $\mathrm{Ca}(\mathrm{OH})_{2}$ solution. The concentration of $\mathrm{Cl}^{-}$ions in the cell was measured weekly, using ion chromatography, for the duration of the experiments. After attaining steady state conditions, the diffusion coefficient of a sample was determined by Equation (1) using the slope of the time versus concentration plot,

$$
\mathrm{D}=\frac{L}{C_{N}}\left(\frac{d C}{d t} \cdot \frac{V}{A}\right)
$$

where $\mathrm{D}$ is the diffusion coefficient $\left(\mathrm{m}^{2} / \mathrm{s}\right), \mathrm{L}$ is the thickness of the specimen $(\mathrm{m}), \mathrm{A}$ is the area of the specimen $\left(\mathrm{m}^{2}\right), \mathrm{V}$ is the volume of cell $\left(\mathrm{m}^{3}\right), \mathrm{C}_{\mathrm{N}}$ is the chloride ion concentration $(\mathrm{mol} / \mathrm{L})$, and $d C / d t$ is the time gradient of concentration $(\mathrm{mol} / \mathrm{L} / \mathrm{s})$ (Goto and Roy, 1981a, 1981b). Two samples were used in the diffusion tests for each type of specimen, and the average of the diffusion coefficients obtained was adopted as the diffusivity.

\subsection{Mercury intrusion porosimetry (MIP)}

Crushed samples (size: approximately $3.0 \mathrm{~mm}$ ) were freeze dried and used for the MIP (AutoPore IV 9500, Micromeritics). The porosity and pore size distribution study was carried out using a mercury intrusion porosimeter capable of generating pressures in the range of sub-ambient to 33,000 psi $(227 \mathrm{MPa})$. The pore radius calculations were done using the Washburn equation.

\section{Modeling}




\subsection{Calculations for an autocorrelation function}

To reconstruct the three-dimensional spatial image of the hardened cement paste, an autocorrelation function (ACF) was used for the different phases (UH, $\mathrm{CH}$, pores detected by BEI, and other phases) in order to generate a binary image from the BEI without the C-S-H phase. The C-S-H phase was not included because, as a matrix, it would act as a continuous phase in the hardened cement paste. A detailed calculation of an ACF has been included in a previous report (Kurumisawa et al., 2012; Bentz, 2000). The following procedure was used to calculate an ACF for this study: The summation $S(x, y)$ is determined for an $\mathrm{M}^{*} \mathrm{~N}$ image using the following equation:

$$
S(x, y)=\sum_{i=1}^{M-x} \sum_{j=1}^{N-y} \frac{I(i, j) \times I(i+x, j+y)}{(M-x)(N-y)}
$$

where $I(x, y)$ is one, if the pixel at location $(x, y)$ contains the phase $(\mathrm{s})$ of interest, and is zero if not. $S(x, y)$ are then converted to a function $S(r)$ for distances $r$ in pixels by bilinear interpolation from the values of $S(x, y)$,

$$
S(r)=\frac{1}{2 r+1} \sum_{l=0}^{2 r} S\left(r, \frac{\pi l}{4 r}\right)
$$

\subsection{Three-dimensional spatial image reconstruction}

An ACF $S(r)$ for each phase mentioned above was used to reconstruct a three-dimensional image of the microstructure. The pixels in the three-dimensional spatial image were assigned random numbers with a normal distribution function, $N(x, y, z)$ that was generated using the Box-Muller method (Bentz, 2000). This random number distribution $N(x, y, z)$ was modified using the filter function $F(x, y$, $z)$, which, in turn, was a function of the ACF $S(r)$. Finally, the resultant image $R(x, y$, z) was generated using the following equations: 


$$
R(x, y, z)=\sum_{i=0}^{30} \sum_{j=0}^{30} \sum_{k=0}^{30} N(x+i, y+j, z+k) * F(i, j, k)
$$

where $F(x, y, z)$ is determined using

$$
F(r)=F(x, y, z)=\frac{\left[S\left(r=\sqrt{x^{2}+y^{2}+z^{2}}\right)-S(0) \times S(0)\right]}{[S(0)-S(0) \times S(0)]}
$$

A threshold operation was carried out to obtain the appropriate volume fractions with respect to the number of pixels in $R(x, y, z)$ that were originally assigned to the respective phases of interest (UH, pores detected by BEI, or $\mathrm{CH}$ ). For example, if a value of $R(x, y, z)$ is higher than the critical threshold, a pixel is assigned to the phase of interest; otherwise, it is assigned to the original phase. The reassigned number of pixels corresponds to the volume fraction measured using the BEI. The reconstructed size of the image was $100^{3}$ voxels with one voxel equivalent to 0.32 $\mu^{3}$, according to the BEI observations. In addition, we confirmed that $32 \mu^{3}$ as a modeling size was sufficient to be able to calculate, from the result, that autocorrelation functions of each phase converged at $10 \mu \mathrm{m}$. We reconstructed three different images with different random numbers to confirm the reproducibility of the model; the application of periodic conditions was also demonstrated. A reconstruction method of three-dimensional images of porous materials with ACF is reported in previous reports, and this method has been used for evaluating the transport properties of porous materials (Adler et al., 1990; Adler and Brenner, 1992; Quiblier, 1984).

\subsection{Prediction of diffusivity of the hardened cement paste}

The diffusivity of the reconstructed three-dimensional image was predicted based on a model proposed in a previous report (Kurumisawa et al., 2012; Garboczi, 1998). Garboczi proposed that the diffusivity is the same as conductivity, as shown in the following Nernst-Einstein relation:

$$
\frac{D}{D_{0}}=\frac{\sigma}{\sigma_{0}}
$$


where $D$ is the measured diffusivity, $D_{0}$ is the diffusivity of the ions being considered in free water, $\sigma_{0}$ is the conductivity of the solution in the pore space, and $\sigma$ is the measured electrical conductivity. For this calculation, the porosity of C-S-H was calculated first using the following equation, which was used in the packing model proposed by a previous report (Jennings et al., 2007):

$$
P_{C-S-H}=0.5-0.0077 \times E_{\text {micro }}
$$

where $P_{C-S-H}$ and $E_{\text {micro }}$ are the porosity and elastic modulus, respectively, of the $\mathrm{C}-\mathrm{S}-\mathrm{H}$ phase. The elastic modulus was determined using the micro-indentation method. The diffusivity of C-S-H was proposed by a previous report (Bejaoui and Bary, 2007) to be a function of the C-S-H porosity $\left(P_{C-S-H}\right)$. It was observed that the low-density (LD) C-S-H and high-density (HD) C-S-H exhibited different diffusivities in that study:

$D_{L D}=1.34 \times 10^{-10} \times P_{C-S-H}^{2.09}$

$D_{H D}=2.02 \times 10^{-11} \times P_{C-S-H}^{1.82}$

where $D_{L D}$ is the diffusivity of LD C-S-H $\left(\mathrm{m}^{2} / \mathrm{s}\right)$ and $D_{H D}$ is the diffusivity of HD $\mathrm{C}-\mathrm{S}-\mathrm{H}\left(\mathrm{m}^{2} / \mathrm{s}\right)$. The aforementioned porosity of C-S-H is calculated using the elastic modulus established with the micro-indentation method, and, thus, the diffusivity of C-S-H was calculated. Diffusivity $D_{L D}$ was used in this study because the water-to-cement ratio of the specimens was 0.6 , which corresponds to $\mathrm{LD} \mathrm{C-S-H}$ as mentioned in the previous report (Tennis and Jennings, 2000). In this study, the diffusivity of chloride ions in the pores detected by BEI was maintained at $1.81 \times$ $10^{-9} \mathrm{~m}^{2} / \mathrm{s}$ (Jensen et al., 1999), where the diffusivity of both $\mathrm{UH}$ and $\mathrm{CH}$ is zero and that of C-S-H was determined using the above expressions, as shown in Table 3. For the determination of C-S-H diffusivity to be in accordance with the measured bulk diffusivity, the diffusivity in the pores was used as input and then, through an iterative process, the diffusivity of C-S-H was changed until the measured bulk diffusion was matched. 


\section{Results and discussion}

\subsection{BEI}

BEI of hardened cement paste is shown in Figure 2, and the histogram of brightness in BEI is shown in Figure 3. After the hardened cement paste was immersed in $\mathrm{NH}_{4} \mathrm{NO}_{3}$ solution, a large pore (shown in black) was observed and calcium hydroxide was found to have disappeared. The area fractions of the phases in the cement paste, as measured by BEI, are shown in Figure 4. An average of 16 images is shown in Figure 4 . The increase in porosity was observed in proportion to the concentration of the $\mathrm{NH}_{4} \mathrm{NO}_{3}$ solution; more than $60 \%$ of the area in the image was occupied by the C-S-H phase, including fine pores, which could not be detected from the BEI. Porosity measured by BEI was almost the same as porosity greater than $0.32 \mu \mathrm{m}$ by MIP, as shown in Figure 5. An inkbottle effect is included in the result of MIP, but it is thought that the effect decreased because large pores are included in the leached samples.

\subsection{Autocorrelation function and three-dimensional spatial image}

The autocorrelation function, calculated from the BEI, is shown in Figure 6. The correlated length of the pore phase increased with the concentration of immersion in $\mathrm{NH}_{4} \mathrm{NO}_{3}$ solution, implying that the pores had enlarged. Thus, there was a greater possibility of the pores connecting to the calcium-leached specimen. The reconstructed three-dimensional spatial image and the pore extraction image are shown in Figure 7. It was possible to reconstruct the three-dimensional spatial image of different phase distributions by using the ACF.

\subsection{Micro-indentation}

The distribution of the micro elastic modulus, measured by micro-indentation and its frequency, is shown in Figure 8 and Figure 9, respectively. The micro elastic modulus in the non-altered specimen was heterogeneously distributed in the specimen. However, the spatial variation is less for the case of leached samples, relative to non-altered samples, as shown in Table 3. It was believed that this was because calcium hydroxide in the specimen had leached out in the presence of $\mathrm{NH}_{4} \mathrm{NO}_{3}$ solution, i.e., most of the remained phase is C-S-H as shown in Figure 4. The median elastic moduli are listed in Table 3. The elastic modulus decreased with increasing concentration of $\mathrm{NH}_{4} \mathrm{NO}_{3}$ solution. The elastic moduli of the non-altered 
and $0.25 \mathrm{M} \mathrm{NH}_{4} \mathrm{NO}_{3}$ specimens were lower than those mentioned in the previous report, and the elastic moduli of the $0.4 \mathrm{M}$ and $0.6 \mathrm{M}$ specimens were higher than those previously reported (Constantinides and Ulm, 2004). This is because the nano-indentations method was applied in the previous study and only the elastic modulus of C-S-H was measured. The influence of phases, such as fine pores or hydrates around the $\mathrm{C}-\mathrm{S}-\mathrm{H}$, is also included in the results of this study.

\subsection{Prediction of diffusion coefficient}

The diffusion coefficients were calculated based on the previous report (Kurumisawa et al., 2012) and the measured diffusion coefficients are plotted in Figure 10. There is no direct correspondence between the two results because, according to the previous report (Bejaoui and Bary, 2007), the diffusion coefficient of $\mathrm{C}-\mathrm{S}-\mathrm{H}$ was determined by the result of non-altered C-S-H. Therefore, in the present study, the diffusion coefficient of altered C-S-H by calcium leaching was determined based on experimental results of diffusion coefficient. That is, the diffusion coefficient of C-S-H was set as an unknown parameter in the model, and the unknown parameter was determined using a spatial image model by the inverse analysis based on the measured diffusion coefficient of hardened cement pastes as mentioned in Section 3.3. The relationship between $\mathrm{CaO}$ leaching, determined by the EPMA measurements, and the calculated diffusion coefficient of C-S-H by inverse analysis is shown in Figure 11. The diffusion coefficient of C-S-H was found to have increased with an increase in $\mathrm{CaO}$ leaching. As a result, it was shown that calcium hydroxide leached out, and the calcium leaching also caused a change in the pore structure of C-S-H. This structural change in C-S-H was also shown in previous reports (Chen et al., 2004; Kurumisawa et al., 2013a, 2013b; Haga et al., 2002). Finally, the diffusion coefficient of the altered specimen from the non-altered specimen was calculated using the relationship between the diffusion coefficients of $\mathrm{C}-\mathrm{S}-\mathrm{H}$ and $\mathrm{CaO}$ leaching, as shown in Figure 11. The predicted and measured diffusion coefficients of hardened cement paste are plotted in Figure 12. The predicted diffusion coefficient, calculated based on the previous report, was also plotted in Figure 12 (Jitendra and Neithalath, 2009). In the previous report, the diffusion coefficient was calculated using equation (5), and porosity, measured by MIP, was used for the calculation of diffusion coefficients. A result of the calculation, almost all of the predicted value based on the previous report was overestimated compared to the experimental value. The predicted value of this study was in sufficient agreement with the experimental value; thus, it was possible to predict 
the diffusivity of the altered cement paste by using the proposed relationship in this study, as shown in Figure 11. However, these results are applicable only to Portland cement paste; their application to blended cement with fly ash or blast furnace slag should be investigated in the future (Kamali et al., 2008).

\section{Conclusion}

An attempt was made to estimate the diffusion coefficient of chloride from the three-dimensional spatial image, which was reconstructed from the autocorrelation function calculated based on the backscattered electron image. It was observed that the diffusion coefficient of C-S-H increased with the extent of calcium leaching. The estimated diffusion coefficient of the altered sample, from the three-dimensional spatial image, was comparable to the measured value. Thus, it was demonstrated that it is possible to predict the diffusion coefficient of the altered cement paste using the proposed model.

Acknowledgments: This research is a part of the results of "Evaluation Experiments of Long-Term Performance of Engineered Barriers (FY2012)" under a grant received from the Agency for Natural Resources and Energy (ANRE) under the Ministry of Economy, Trade and Industry (METI), Japan.

\section{References}

Adler, P. M., Jacquin, C. G., Quiblier, J. A., 1990. Flow in simulated porous media. International Journal of Multiphase Flow, 16(4) 691-712

Adler, Pierre., Brenner, Howard., 1992. Porous media. Butterworth-Heinemann Series in Chemical Engineering.

Bejaoui, S., Bary, B., 2007. Modeling of the link between microstructure and effective diffusivity of cement pastes using a simplified composite model. Cement and Concrete Research, 37(3) 469-480.

Bentz, Dale P., 2000. CEMHYD3D: A Three-Dimensional Cement Hydration and Microstructure Development Modelling Package Version 2.0. NISTIR 6485.

Burlion, N., Bernard, D., Chen, D., 2006. X-ray microtomography: application to microstructure analysis of a cementitious material during leaching process. Cement and Concrete Research, 36(2) 346-357. 
Carde, C., François, R., 1997. Effect of the leaching of calcium hydroxide from cement paste on mechanical and physical properties. Cement and Concrete Research, 27(4) 539-550.

Chen, J. J., Thomas, J. J., Taylor, H. F., Jennings, H. M., 2004. Solubility and structure of calcium silicate hydrate. Cement and Concrete Research, 34(9) 1499-1519.

Constantinides, G., Ulm, F. J., 2004. The effect of two types of CSH on the elasticity of cement-based materials: Results from nanoindentation and micromechanical modeling. Cement and concrete research, 34(1) 67-80.

Garboczi, E.J., 1998. Finite Element and Finite Difference Programs for Computing the Linear Electric and Elastic Properties of Digital Images of Random Materials. National Institute of Standards and Technology Internal Report 6269.

Goto, S., Roy, D. M., 1981a. Diffusion of ions through hardened cement pastes. Cement and Concrete Research, 11(5) 751-757.

Goto, S., Roy, D. M., 1981b. The effect of w/c ratio and curing temperature on the permeability of hardened cement paste. Cement and Concrete Research, 11(4) 575-579.

Haga, K., Shibata, M., Hironaga, M., Tanaka, S., Nagasaki, S., 2002. Silicate anion structural change in calcium silicate hydrate gel on dissolution of hydrated cement. Journal of nuclear science and technology, 39(5) 540-547.

Head, M. K., Buenfeld, N. R., 2006. Confocal imaging of porosity in hardened concrete. Cement and concrete research, 36(5) 896-911.

Igarashi, S., Kawamura, M., Watanabe, A., 2004. Analysis of cement pastes and mortars by a combination of backscatter-based SEM image analysis and calculations based on the Powers model. Cement and Concrete Composite, 26 977-985

Iqbal, P. O. N., Ishida, T., 2009. Modeling of chloride transport coupled with enhanced moisture conductivity in concrete exposed to marine environment. Cement and Concrete Research, 39(4) 329-339.

Jennings, H. M., Thomas, J. J., Gevrenov, J. S., Constantinides, G., Ulm, F. J., 2007. A multi-technique investigation of the nanoporosity of cement paste. Cement and Concrete Research, 37(3) 329-336.

Jensen, O. M., Hansen, P. F., Coats, A. M., Glasser, F. P., 1999. Chloride ingress in cement paste and mortar. Cement and Concrete Research, 29(9) 1497-1504. 
Jitendra, J. Neithalath, N., 2009. Analysis of calcium leaching behavior of plain and modified cement pastes in pure water. Cement and Concrete Composites, 31(3) 176-185.

Kamali, S., Moranville, M., Leclercq, S., 2008. Material and environmental parameter effects on the leaching of cement pastes: experiments and modelling. Cement and Concrete Research, 38(4) 575-585.

Kurumisawa, K., Nawa, T., Owada, H., 2012. Prediction of the diffusivity of cement-based materials using a three-dimensional spatial distribution model. Cement and Concrete Composites, 34(3) 408-418.

Kurumisawa, K., Owada, H.,Shibata, M., 2013a. Mechanical properties of deteriorated hardened cement paste. In Mechanics and Physics of Creep, Shrinkage, and Durability of Concrete: Proceedings of the Ninth International Conference on Creep, Shrinkage, and Durability Mechanics (CONCREEP-9), 285-292

Kurumisawa, K., Nawa, T., Owada, H., Shibata, M., 2013b. Deteriorated hardened cement paste structure analyzed by XPS and ${ }^{29} \mathrm{Si} \mathrm{NMR}$ techniques. Cement and concrete research, 52 190-195.

Moranville, M., Kamali, S., Guillon, E., 2004. Physicochemical equilibria of cement-based materials in aggressive environments-experiment and modeling. Cement and Concrete Research, 34(9) 1569-1578.

Oliver, W. C., Pharr, G. M., 1992. An improved technique for determining hardness and elastic modulus using load and displacement sensing indentation experiments. Journal of materials research, 7(06) 1564-1583.

Quiblier, J. A., 1984. A new three-dimensional modeling technique for studying porous media. Journal of Colloid and Interface Science. 98(1) 84-102.

Radioactive Waste Management Funding and Research Center(RWMC), 2013. H24 Report of Project for Evaluation on the Long-term Performance of Engineered Barrier System.

Scrivener, K., Snellings, R., Lothenbach, B., 2015. A Practical Guide to Microstructural Analysis of Cementitious Materials, CRC Press.

Tennis, P. D., Jennings, H. M., 2000. A model for two types of calcium silicate hydrate in the microstructure of Portland cement pastes. Cement and Concrete Research, 30(6) 855-863.

Wan, K., Li, Y., Sun, W., 2012. Application of tomography for solid calcium distributions in calcium leaching cement paste. Construction and Building Materials, 36 913-917. 
Wan, K., Xu, Q., Li, L., Sun, W., 2013. 3D porosity distribution of partly calcium leached cement paste. Construction and Building Materials, 48 11-15.

Yio, M. H. N., Mac, M. J., Wong, H. S., Buenfeld, N. R., 2015. 3D imaging of cement - based materials at submicron resolution by combining laser scanning confocal microscopy with serial sectioning. Journal of microscopy, 258(2) 151-169.

Yokozeki, K., Watanabe, K., Sakata, N., Otsuki, N., 2004. Modeling of leaching from cementitious materials used in underground environment. Applied clay science, 26(1) 293-308.

Zhu, W., Bartos, P. J., 2000. Application of depth-sensing microindentation testing to study of interfacial transition zone in reinforced concrete. Cement and Concrete Research, 30(8) 1299-1304. 
Table 1: Chemical composition of cement (wt\%)

\begin{tabular}{|c|c|c|c|c|c|c|c|}
\hline $\mathrm{SiO}_{2}$ & $\mathrm{Al}_{2} \mathrm{O}_{3}$ & $\mathrm{Fe}_{2} \mathrm{O}_{3}$ & $\mathrm{CaO}$ & $\mathrm{MgO}$ & $\mathrm{SO}_{3}$ & $\mathrm{Na}_{2} \mathrm{O}$ & $\mathrm{K}_{2} \mathrm{O}$ \\
\hline 21.31 & 5.39 & 2.75 & 64.57 & 1.76 & 2.05 & 0.17 & 0.4 \\
\hline
\end{tabular}

Table 2: Conditions of hardened cement pastes

\begin{tabular}{|l|c|}
\hline \multicolumn{1}{|c|}{ Conditions } & \\
\hline Concentrations of ammonium nitrate $(\mathrm{mol} / \mathrm{L})$ & $0.25,0.40,0.60$ \\
\hline Liquid/Solid ratio (mass) & 30 \\
\hline Leaching period & 7 days \\
\hline $\mathrm{NH}_{4} \mathrm{NO}_{3} /$ Solid ratio(mass) & $0.6,1.0,1.4$ \\
\hline
\end{tabular}

Table 3: Median value of microelastic modulus of hardened cement pastes, C-S-H porosity, and diffusivity of C-S-H calculated with previous report.

\begin{tabular}{|c|c|c|c|}
\hline Specimen & $\begin{array}{c}\text { Microelastic } \\
\text { modulus(GPa) }\end{array}$ & $\begin{array}{c}\text { C-S-H } \\
\text { porosity }\end{array}$ & $\begin{array}{c}\text { Diffusivity of C-S-H } \\
\times 10^{-10}\left(\mathrm{~m}^{2} / \mathrm{s}\right) \text { calculated } \\
\text { by previous report }\end{array}$ \\
\hline Non-altered & $14.3 \pm 4.8$ & 0.39 & 0.187 \\
\hline $0.25 \mathrm{M} \mathrm{NH}_{4} \mathrm{NO}_{3}$ & $14.1 \pm 3.9$ & 0.391 & 0.188 \\
\hline $0.4 \mathrm{M} \mathrm{NH}_{4} \mathrm{NO}_{3}$ & $9.5 \pm 3.1$ & 0.427 & 0.226 \\
\hline $0.6 \mathrm{M} \mathrm{NH}_{4} \mathrm{NO}_{3}$ & $9.4 \pm 3.0$ & 0.428 & 0.227 \\
\hline
\end{tabular}




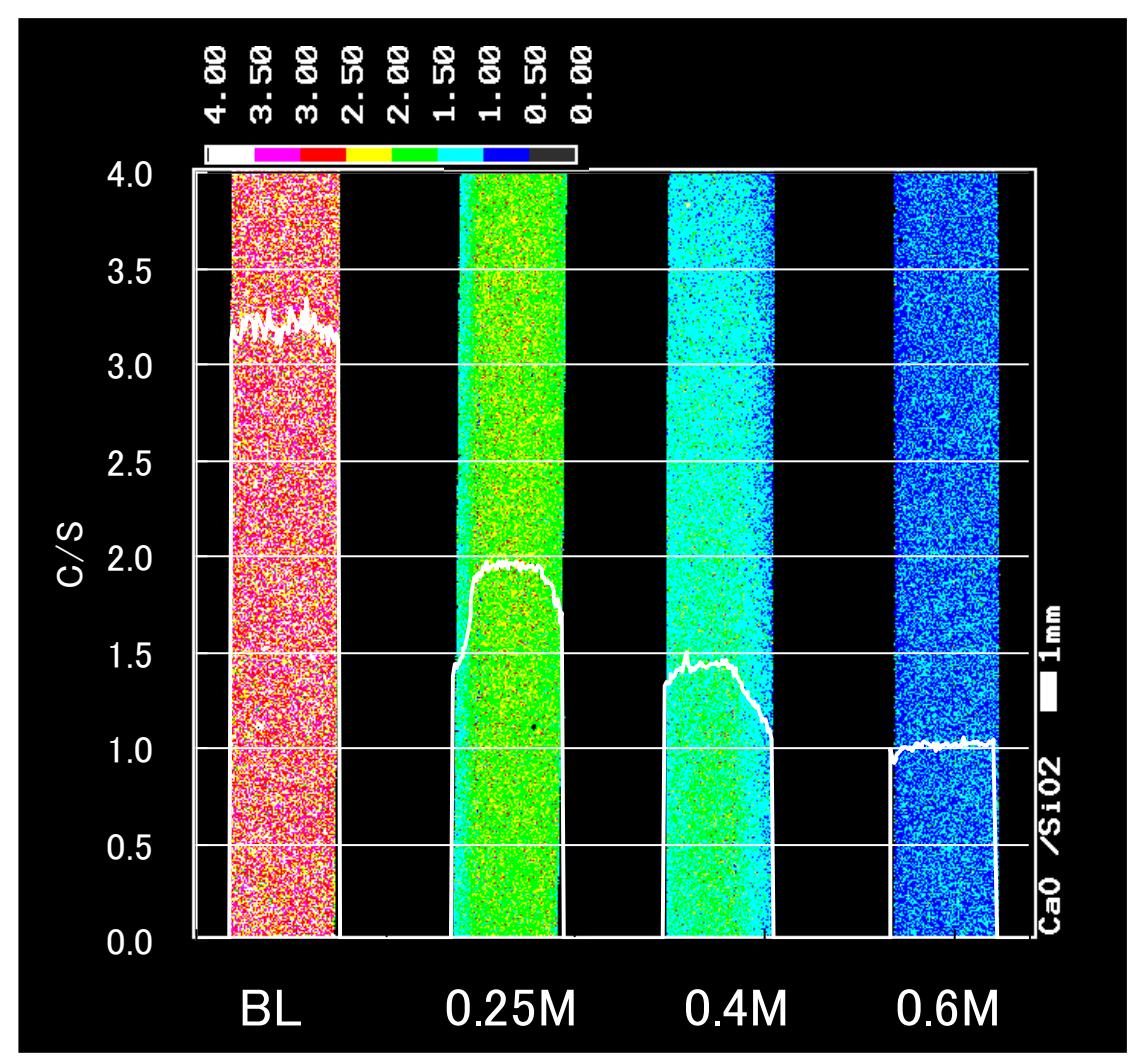

Figure 1: $\mathrm{CaO} / \mathrm{SiO}_{2}$ distribution of specimens measured by EPMA

(Average $\mathrm{CaO} / \mathrm{SiO}_{2}$ is $\mathrm{BL}: 3.2,0.25 \mathrm{M}: 1.8,0.4 \mathrm{M}: 1.3,0.6 \mathrm{M}: 1.0$. ) 

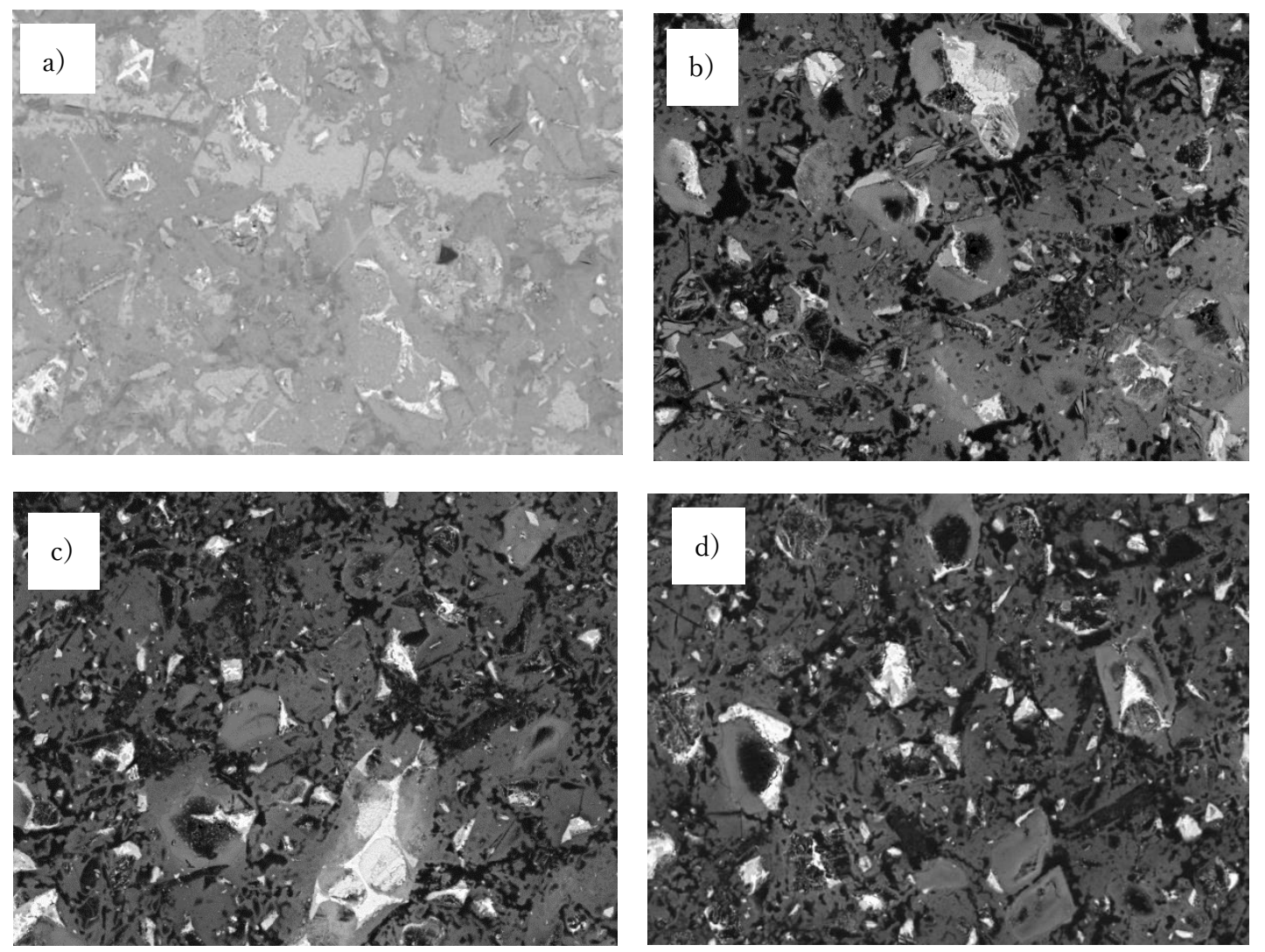

Figure 2: Backscattered electron image of hardened cement paste $(200 * 150 \mu \mathrm{m})$, a) non-altered cement paste, b) specimen immersed in $0.25 \mathrm{M} \mathrm{NH}_{4} \mathrm{NO}_{3}$, c) specimen immersed in $0.4 \mathrm{M} \mathrm{NH}_{4} \mathrm{NO}_{3}, \mathrm{~d}$ ) specimen immersed in $0.6 \mathrm{M} \mathrm{NH}_{4} \mathrm{NO}_{3}$

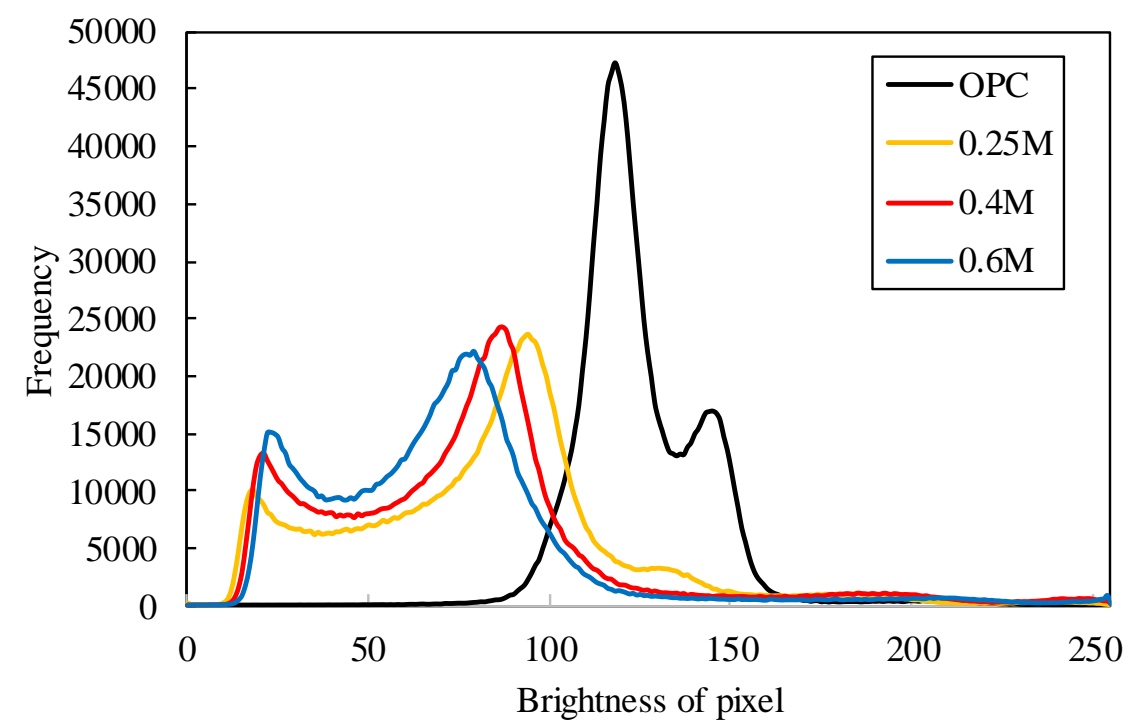

Figure 3: Brightness of backscattered electron image of hardened cement paste 


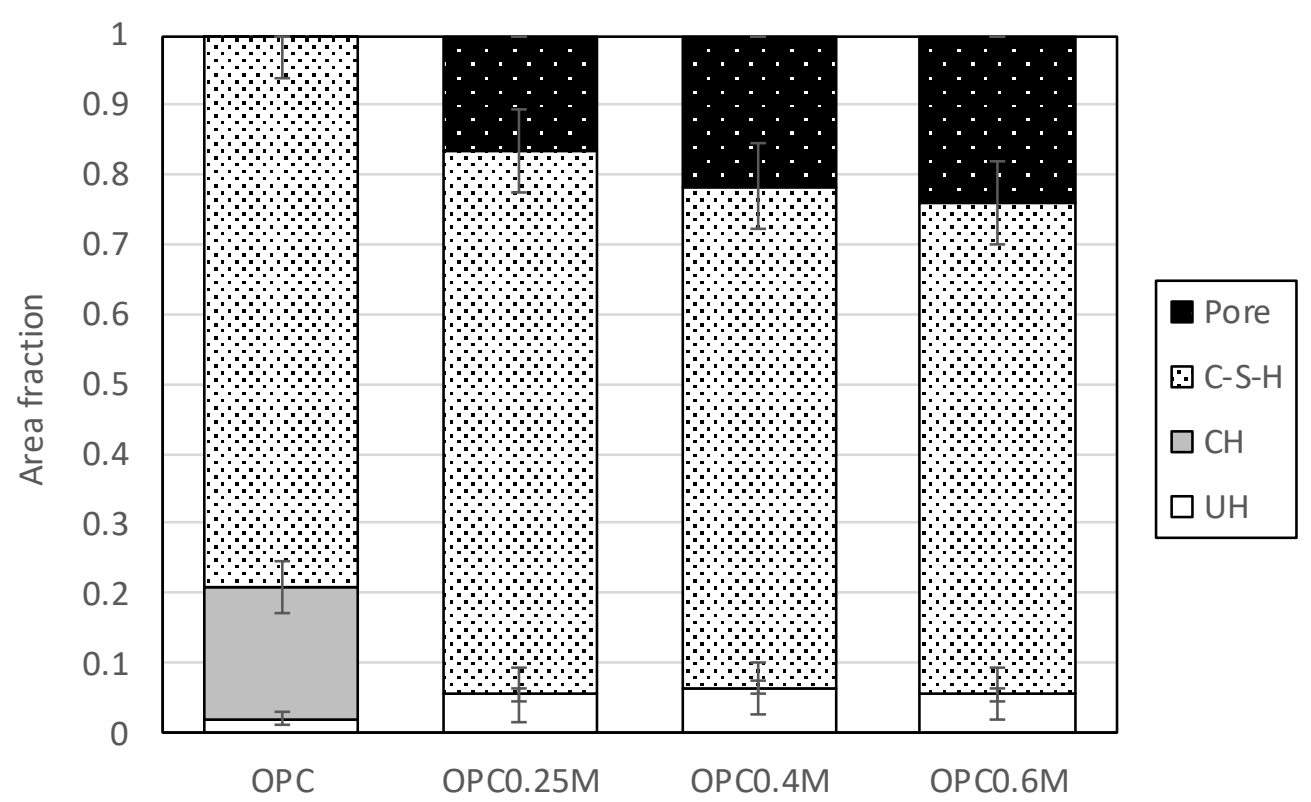

Figure 4: Area fraction of phases measured using backscattered electron image

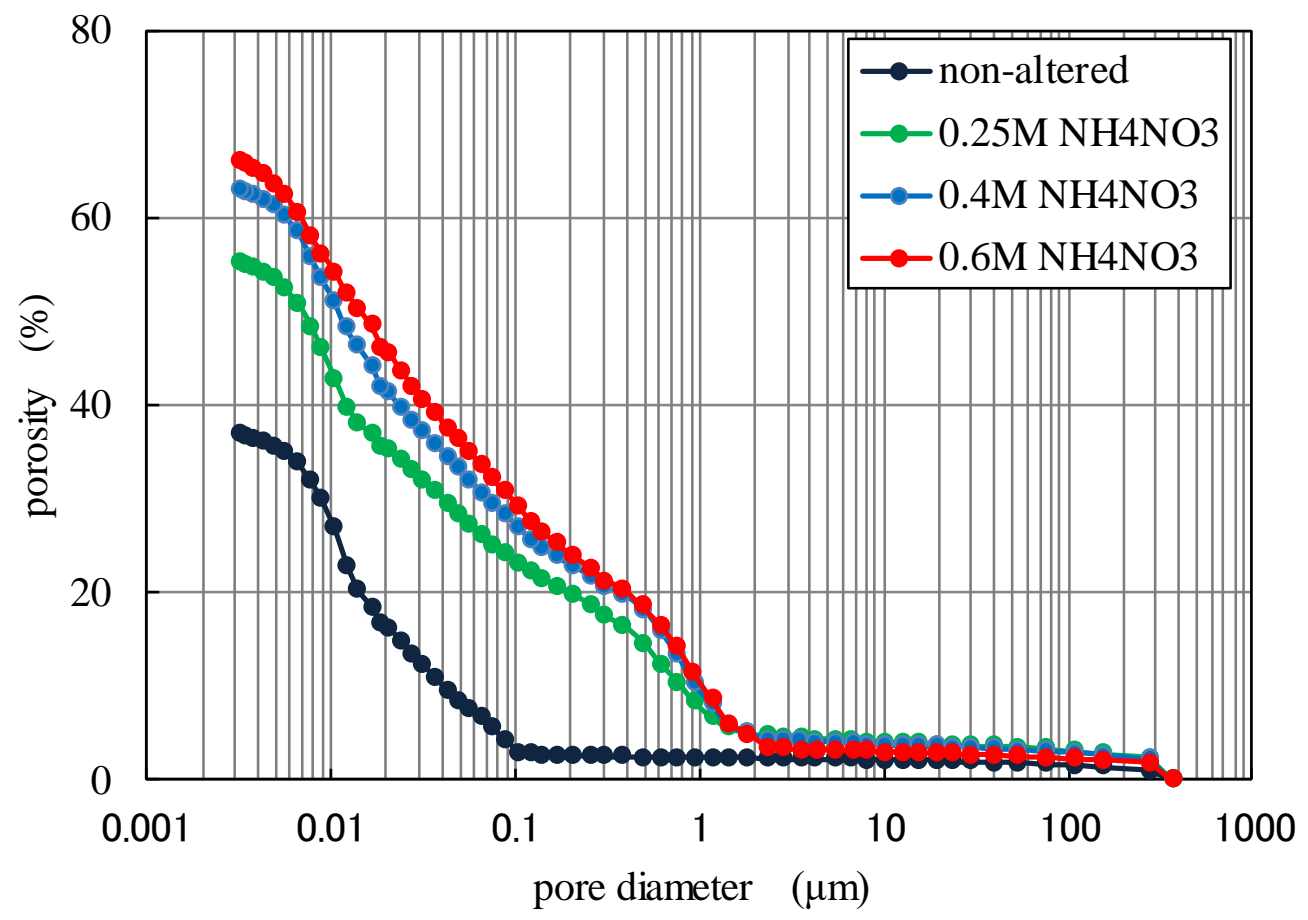

Figure 5: Pore size distribution of specimens measured by MIP 

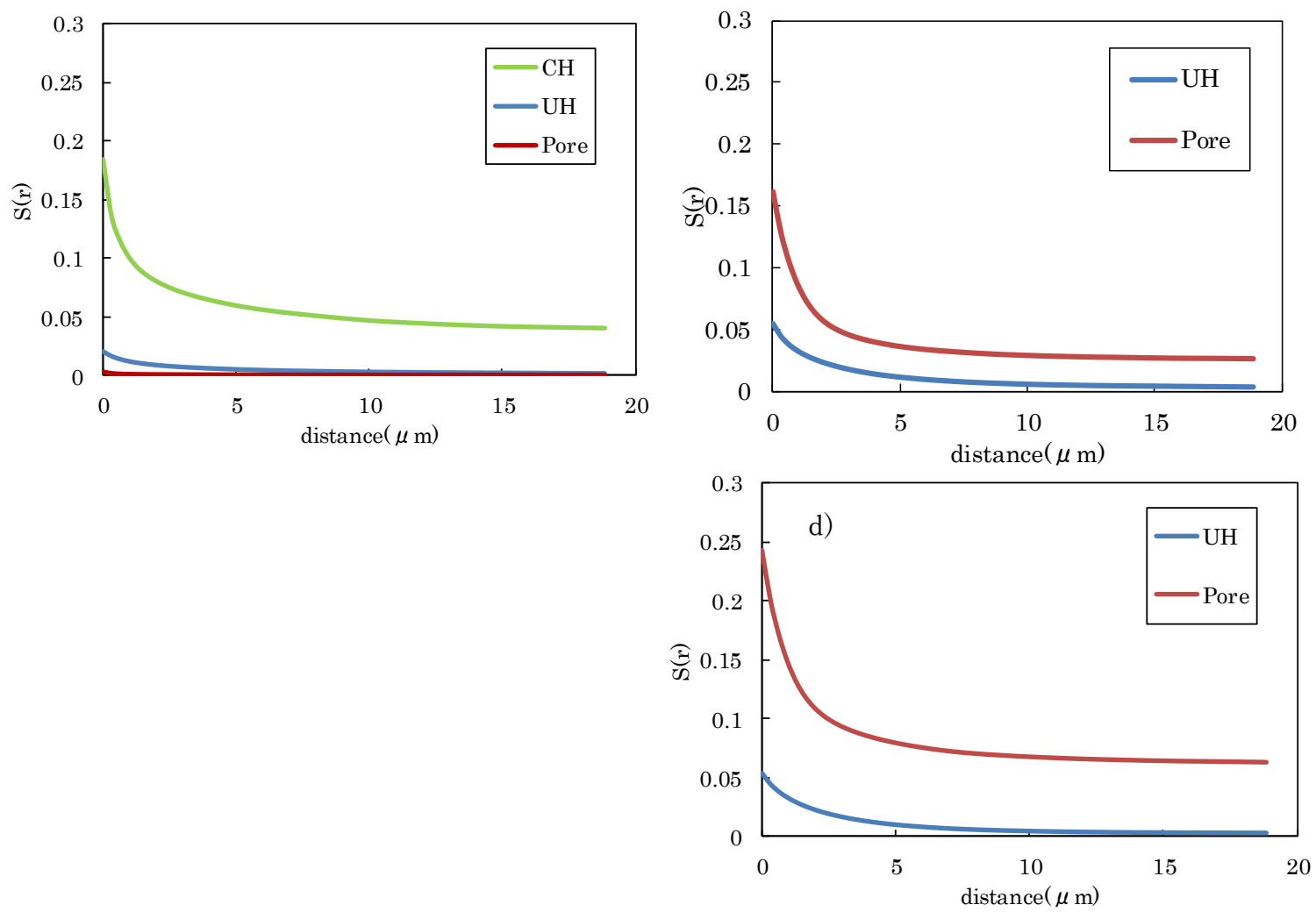

Figure a) Itocorrelation function of hardened ce b) paste, a) non-altered cement paste, b) specimen immersed in $0.25 \mathrm{M} \mathrm{NH}_{4} \mathrm{NO}_{3}$, c) specimen immersed in $0.4 \mathrm{M}$ $\mathrm{NH}_{4} \mathrm{NO}_{3}, \mathrm{~d}$ ) specimen immersed in 0.6 $\mathrm{M} \mathrm{NH}_{4} \mathrm{NO}_{3}$

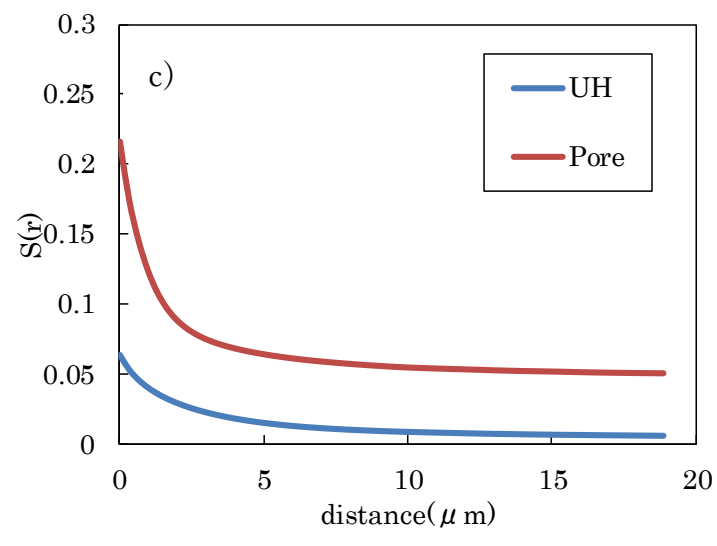


a)
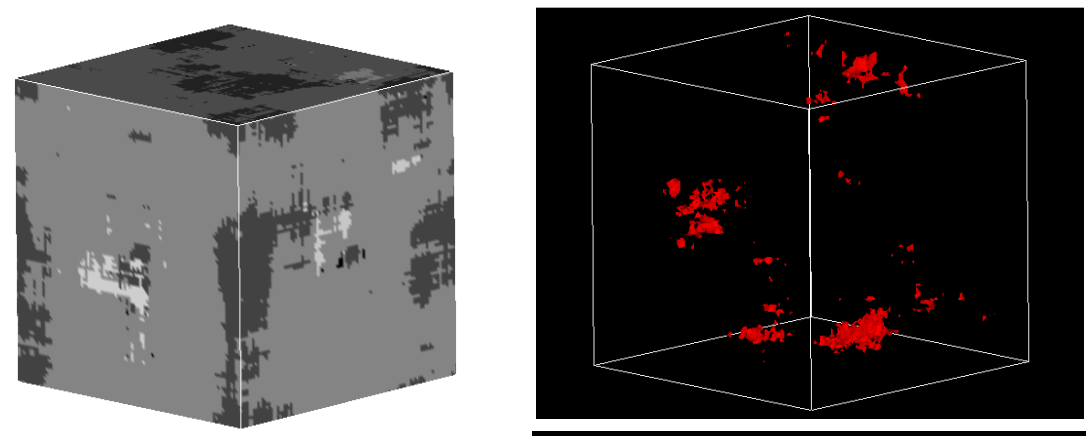

b)
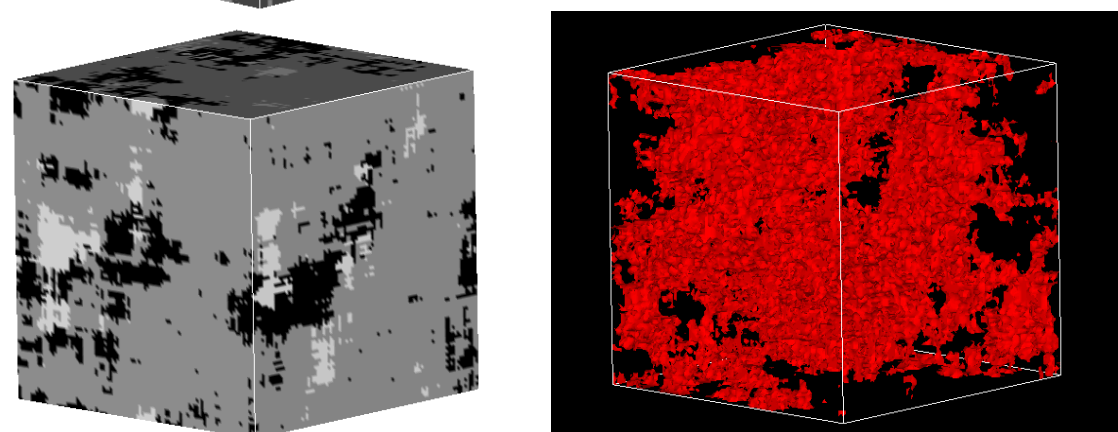

c)
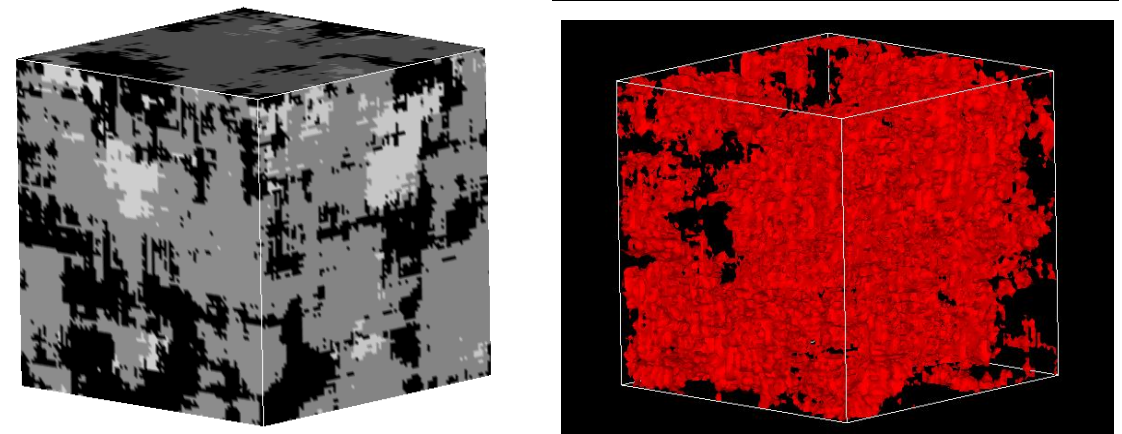

d)
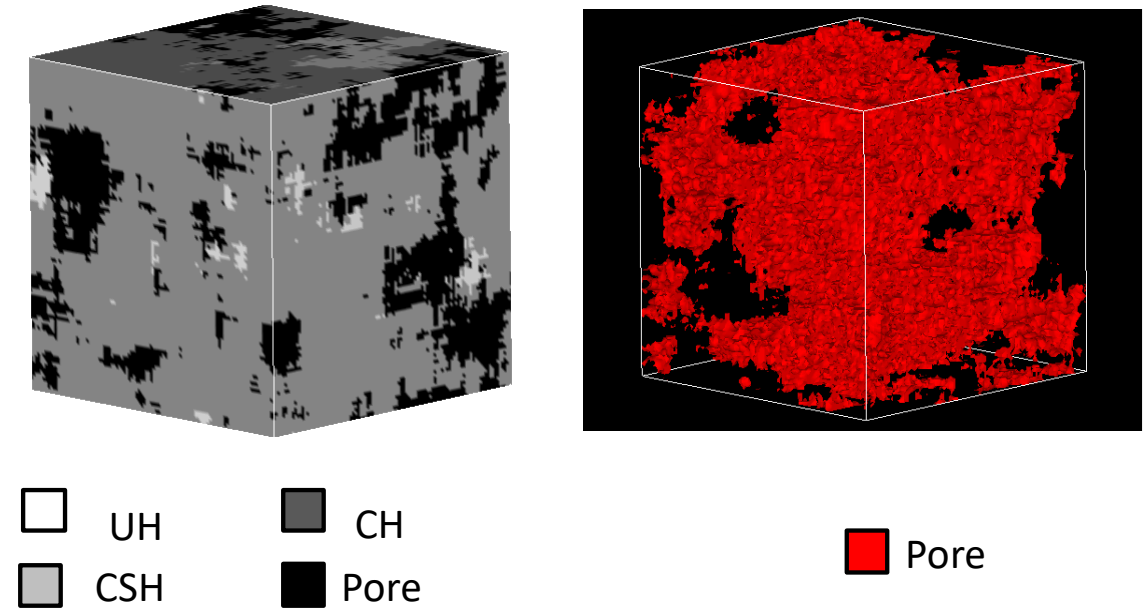

Figure 7: Reconstructed 3D spatial image of hardened cement paste, left: view of 3D image, right: view of extraction of pores, a) non-altered cement paste, b) specimen 
immersed in $0.25 \mathrm{M} \mathrm{NH}_{4} \mathrm{NO}_{3}$, c) specimen immersed in $0.4 \mathrm{M} \mathrm{NH}_{4} \mathrm{NO}_{3}$, d) specimen immersed in $0.6 \mathrm{M} \mathrm{NH}_{4} \mathrm{NO}_{3}$

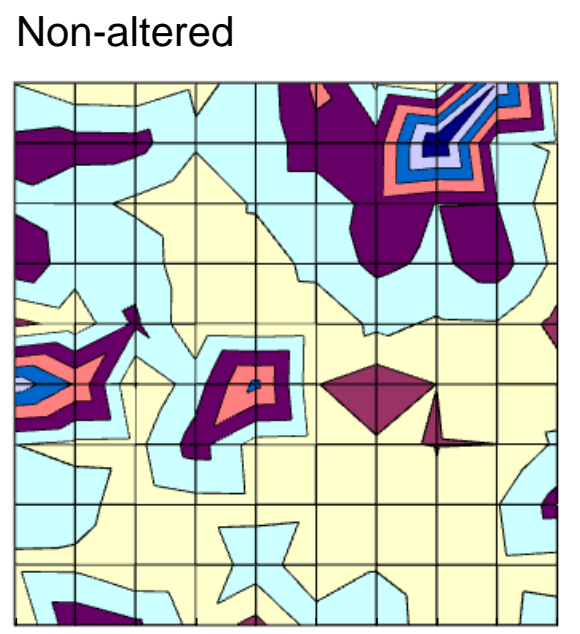

$0.25 \mathrm{M} \mathrm{NH}_{4} \mathrm{NO}_{3}$
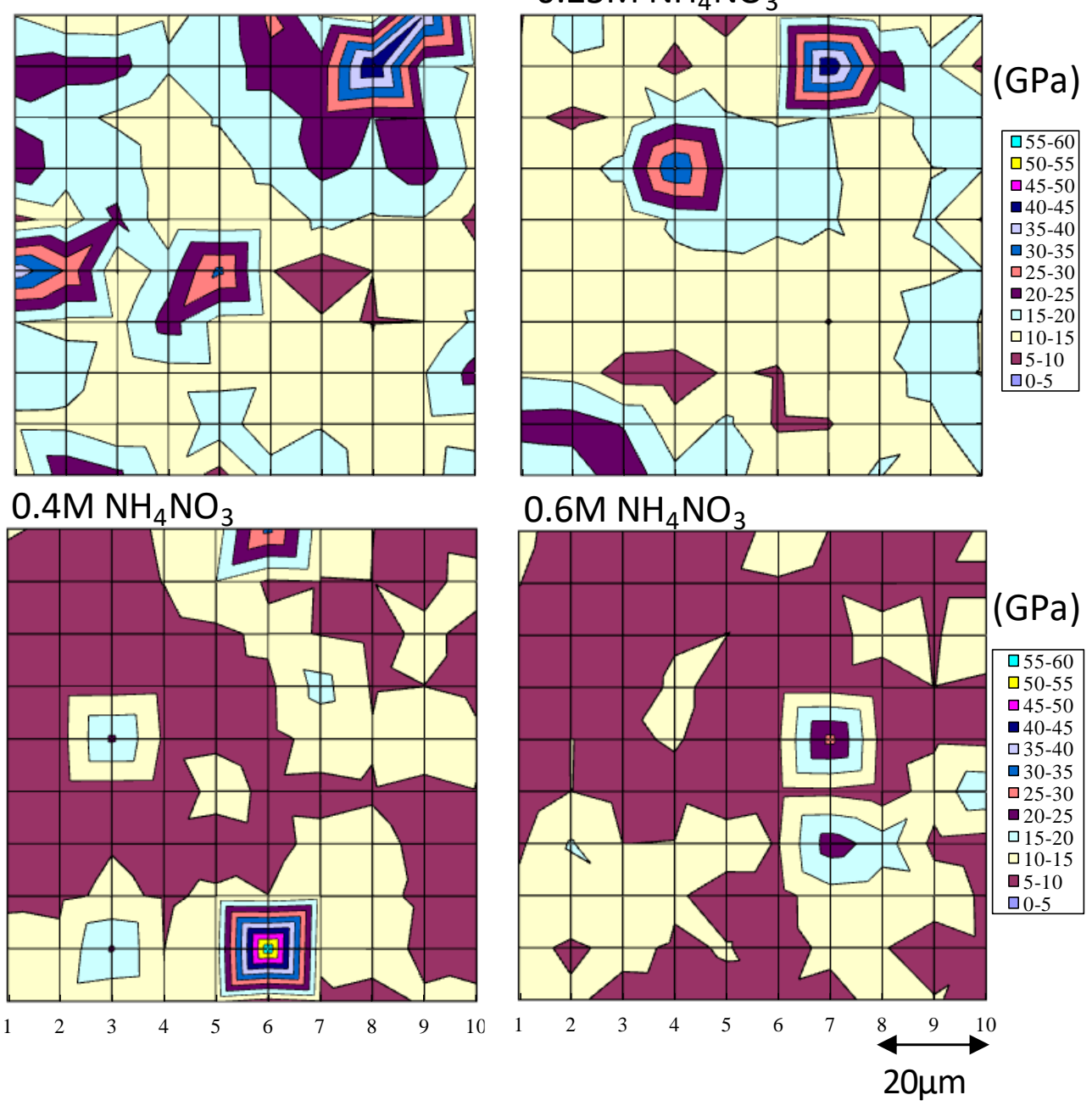

Figure 8: Distribution of micro elastic modulus in hardened cement paste 


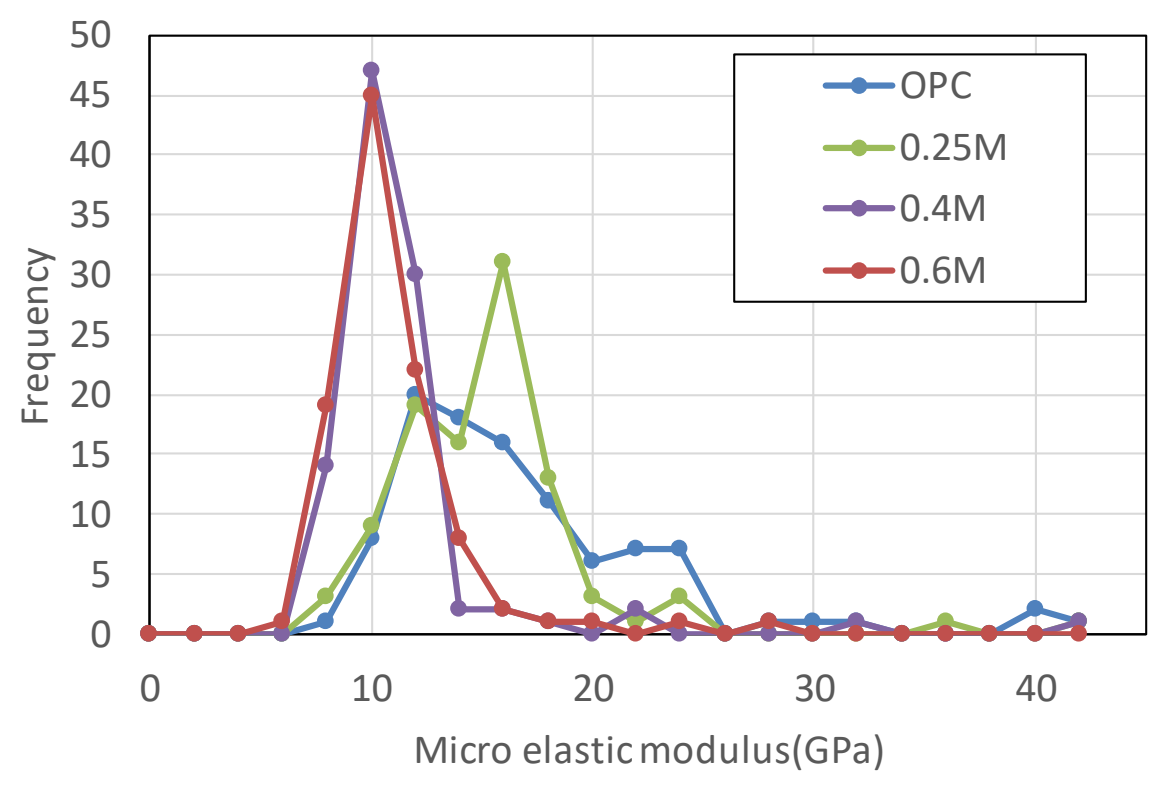

Figure 9: Frequency of micro elastic modulus in hardened cement paste

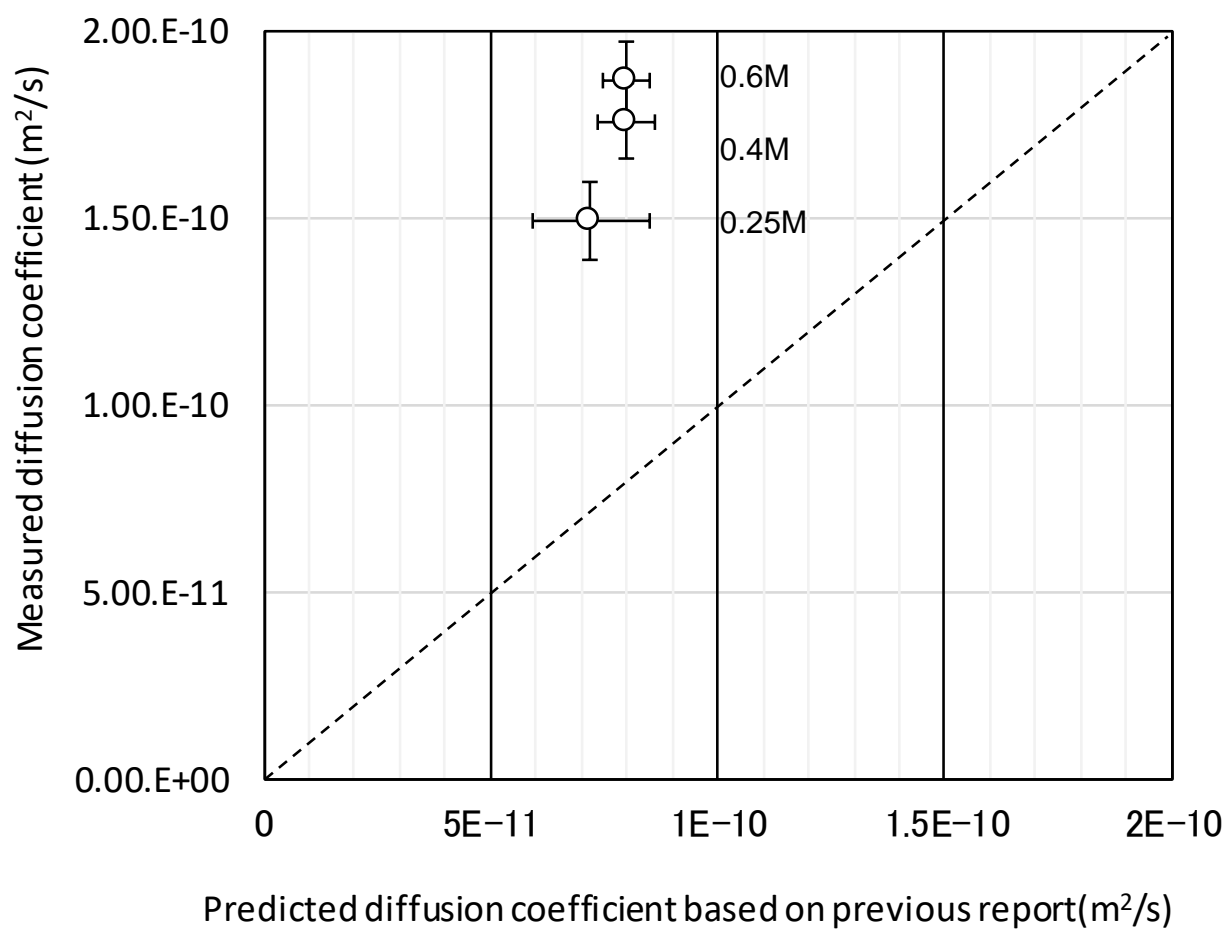

Figure 10: Plot of measured and predicted chloride diffusion coefficient of hardened cement paste calculated based on previous report 


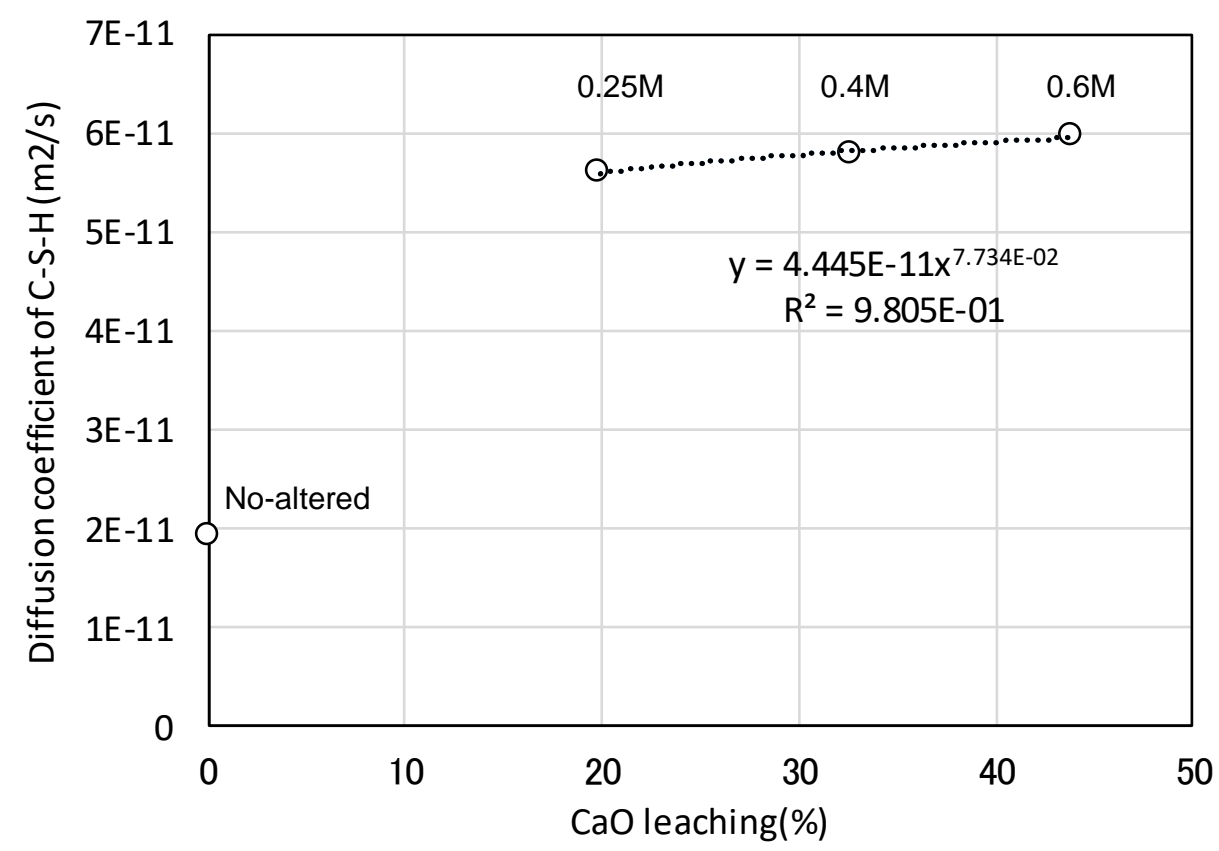

Figure 11: Plot of $\mathrm{CaO}$ leaching and diffusivity of C-S-H calculated using inverse analysis

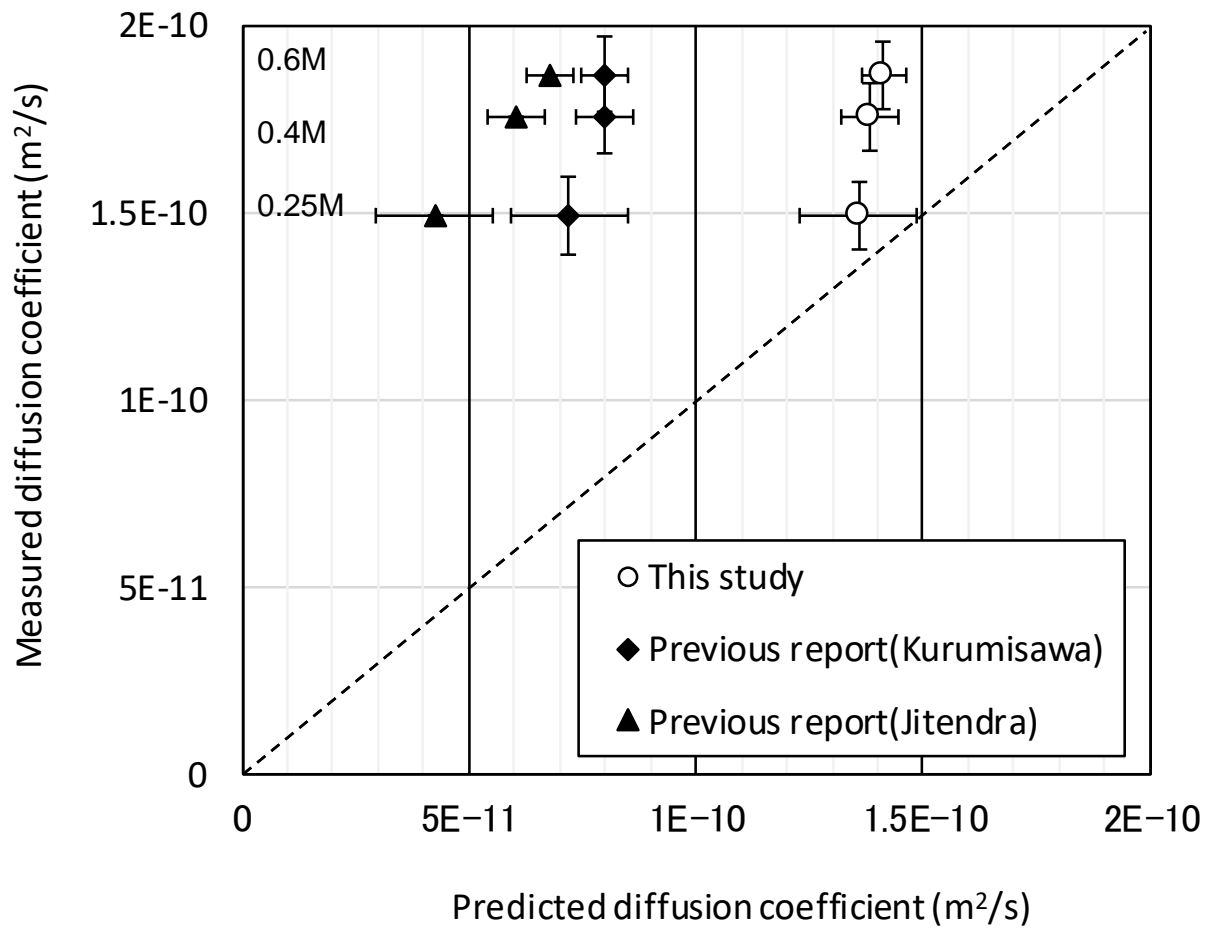

Figure 12: Plot of measured and predicted chloride diffusion coefficient of hardened cement paste calculated using the proposed relations 
The 3D spatial image of the cement paste was produced using the auto-correlation functions.

An attempt was made to estimate the diffusion coefficient of chloride from the 3D spatial image.

The estimated diffusivity from the 3D image was found to be comparable to the measured value.

It is possible to predict the diffusivity of the altered cement paste by using the proposed model. 